\title{
An Efficient Component based Analysis of Optical Character Recognition
}

\author{
G.Michael, C. Nalini, C. Geetha
}

\begin{abstract}
Optical character acknowledgment alludes to the way toward understanding pictures of written by hand, typescript, or printed content into an arrangement comprehended by machines for the motivation behind modifying, ordering/looking, and to reduce size. Optical character acknowledgment is the understanding of pictures of written by hand, typescript or printed content into machine-editable content by mechanically or electronically. The purpose of the present hypothesis is to find the numbers and English letter sets picture of times new roman, Arial, Arial square size of 72, 48 by using imperative part examination. Head Components Analysis (PCA) is a functional and standard measurable instrument in current information examination that has discovered application in various zones, for example, face acknowledgment, picture pressure and neuroscience. It has been called one of the most valuable outcomes from connected straight polynomial math. PCA is a clear, non-parametric technique for splitting appropriate data from confounding instructive indexes.
\end{abstract}

Keywords-Analysis, Recognition

\section{INTRODUCTION}

Optical character acknowledgment alludes to the way toward deciphering pictures of written by hand, typescript, or printed content into an arrangement comprehended by machines for motivation behind modifying, ordering/looking, and to reduce size. Optical character acknowledgment is the understanding of pictures of written by hand, typescript or printed content into machine-editable text mechanically or electronically. The purpose of the present hypothesis is to find the numbers and English letter sets picture of times new roman,arial,arial square size of 72,48 by using indispensable part examination. Head Components Analysis (PCA) is a functional and standard measurable apparatus in present day information investigation that has discovered application in various regions, for instance, face affirmation, picture weight and neuroscience. It has been called one of the most important results from associated direct polynomial math. PCA is a clear, non-parametric strategy for extricating appropriate data from confounding instructive collections. It displays a guide for how to decrease an intricate instructive record to a lower estimation to reveal the concealed, streamlined structures that usually underlie it. In this undertaking we present a far reaching exchange of PCA and furthermore execute it on by utilizing MATLAB. PCA has

Revised Manuscript Received on October 22, 2019.

G.Michael *, Department of CSE, Bharath Institute of Higher Education and Research, Chennai, Tamilnadu, India.

C. Nalini, Department of CSE, Bharath Institute of Higher Education and Research, Chennai, Tamilnadu, India.

C. Geetha, Department of CSE, Bharath Institute of Higher Education and Research, Chennai, Tamilnadu, India. been connected in a wide assortment of zones, for example, agribusiness, science, science, climatology, demography, financial matters, sustenance look into, hereditary qualities, topography, meteorology, brain research. Head part investigation is a strategy for recognizing structures in data, and conveying the data in order to highlight their comparability and complexities [12]. Since example in instructive can be hard to discover in data of high evaluation, where merits of pictorial representation is not available. In this way, PCA is the integral asset for breaking down instructive. Another primary bit of leeway of PCA is that we discover the models in the data, and pack the data, that is, by reducing the amount of estimations, missing much loss of information.

\section{CHARACTER RECOGNITION}

Character acknowledgment, typically truncated to optical character affirmation or shortened OCR, is the understanding of pictures of physically composed, typescript or printed content (generally speaking gotten by a scanner) into machine-editable substance mechanically or electronically. It is a field of research in model affirmation, man-made thinking and machine vision. Regardless of the way that educational research in the field continues, the accentuation on character affirmation has moved to execution of illustrated procedures $[9,10]$. For some, archive info errands, character acknowledgment is the most practical and quick technique accessible. Furthermore, every year, the innovation liberates sections of land of extra room once offered over to file organizers and boxes loaded with paper records.

Character acknowledgment is otherwise called Optical Character Recognition (OCR) since it manages acknowledgment of optically handled characters instead of, for instance, attractively prepared ones. The starting point of character acknowledgment can be found as ahead of schedule as in 1870, however the advanced rendition of OCR showed up in the center of the 1940s with the improvement of computerized PCs. Its primary territory of intrigue was information preparing, with application to the business world. The foremost inspiration for the improvement of OCR frameworks is the need to adapt to the colossal surge of paper, for example, bank checks, business structures, government records, mail arranging created by the extending society and universal associations. Since the starting point of OCR frameworks [5, 6], broad research has been done and an enormous number of specialized papers have been

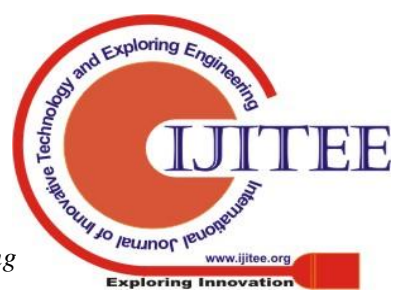


distributed by analysts around there. Numerous systems and exploratory outcomes have been distributed in the writing.

As of late, new arrangement draws near, for example, neural systems, and plan approachs, for example, classifier blend and parallel element extraction, have recharged interests in this field. As OCR innovation looks for applications in increasingly convoluted, ongoing situations, the basis for effective calculations and designs turns out to be progressively thorough [8].

\section{SYSTEM ANALYSIS}

\section{EXISITING SYSTEM:}

At the point when the goals of the character pictures becomes bigger, neural system preparing will in general be delayed because of all the more handling for bigger information grid. In the event that the character pictures have lower goals, the preparation procedure is a lot quicker. In any case, some significant subtleties may be lost. Character acknowledgment gadget is one of such brilliant gadgets that gain fractional human knowledge with the capacity to catch and perceive different characters in various dialects. Initially multilevel neural preparing with changes in the information preparing vectors is embraced in existing framework to get its favorable position in preparing higher goals character pictures [11]. Also specific thresholding utilizing least separation method is proposed to be utilized to build the

Disadvantages of Existing System

- Difficult to create template

- The System not given that much accuracy

- Execution time is high

\section{PROPOSED SYSTEM:}

Proposed System is to find the numbers and English letters all together picture of times new roman, arial, arial square size of 72,48 by utilizing head part examination [7]. Head Components Analysis (PCA) is a handy and standard factual instrument in present day information examination which has different application in many regions, for instance, face affirmation, picture weight and neuroscience. It has been called one of the most significant results from associated direct factor based math [4]. The other principle bit of leeway of PCA is that we discover the examples in the information, and pack the information, that is, by reducing the quantity of measurements, absent much loss of data.

Advantages of Proposed System

- Easy to create template

- The System give better accuracy than existing system

- The system provides less execution time

\section{SYSTEM MODULE}

The system module consists of three steps: preprocessing, feature extraction, recognition that is shown in figure. The initial phase in the picture handling chain comprises of preprocessing, approximately characterized, by preprocessing we mean any activity of which the information comprises of sensor information, and of which the yield is a full picture. Preprocessing tasks by and large fall into three classes: picture securing, picture change, morphological operations. Then the next step is the highlight extraction, is degree of precision of character acknowledgment.

finished by head segment investigation principal component analysis [PCA] and finally recognition process take place [3].

\section{PREPROCESSING:}

Electronic picture verifying is the creation of cutting edge pictures, regularly from a physical scene. The term is normally expected to recommend or consolidate the taking care of, weight, accumulating, printing, and show of such pictures. The most common strategy is by computerized photography with an advanced camera however different strategies are likewise utilized [1].

\section{IMAGE CONVERSIONS}

In picture changes includes three phases: RGB picture to Gray picture and Gray picture to Binary picture and a short time later Binary picture into Edge picture.

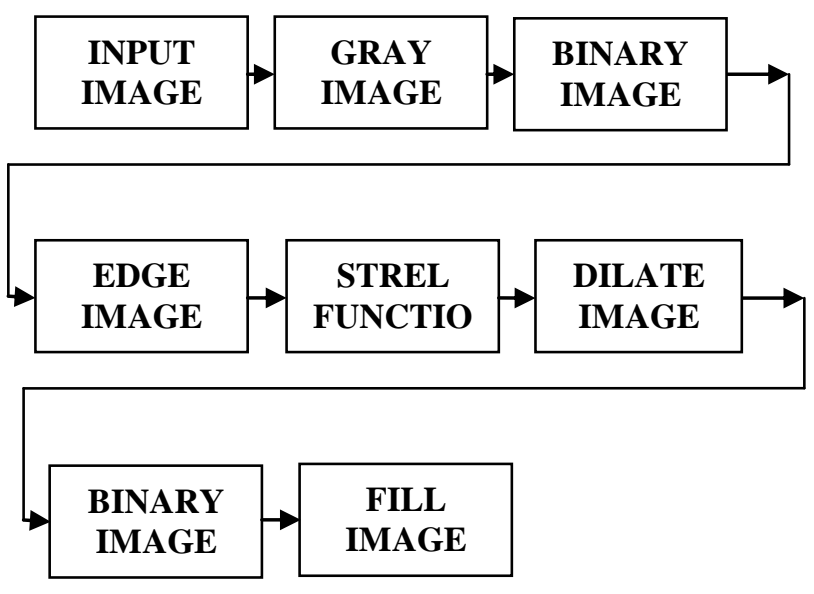

Fig 1: Block diagram of preprocessing

\section{FEATURE EXTRCTION}

Morphological operations are affecting the form, structure or shape of an object. Applied on binary images (black \& white images - Images with only 2 colors: black and white). They are used in pre or post processing (filtering, thinning, and pruning) or for getting a representation or description of the state of items/districts (limits, skeletons arched hulls).The two head morphological tasks are expansion and disintegration [1]. Widening enables items to grow, in this manner possibly filling in little gaps and associating disjoint articles. Disintegration psychologists questions by scratching endlessly (dissolving) their limits. These activities can be redone for an application by the correct choice of the organizing component, which decides precisely how the articles will be expanded or disintegrated.

Documentations:

Dark pixel: in grayscale values for a 8 bits/pixel ordered picture its worth will be 0 . White pixel: in grayscale values for a 8 bits/pixel recorded picture its worth will be 255.Morphological operations consists of edge image into dilate image using of structural element. Expand picture into parallel picture and after that paired picture into filling picture. 


\section{RECOGNITION:}

Boss part examination is a straight change, which rotates the center point of picture space along lines of most prominent contrast.

The upset relies upon the even eigenvectors of the covariance system made from a case of picture data from the information channels [2]. The yield from this change is another game plan of picture channels, which are also suggested as eigen channels. PCA can be used to address such, inter- band correlation and separate that correlation into components (layers).The components generated with layers of information are unique in their information content.PCA also allow to extract redundant data from each input band and compact into fewer bands after reducing the dimensionality of the data. The primary utilization of PCA is to decrease the dimensionality of an informational collection while holding however much data as could reasonably be expected. It computes a compact and optimal description of the data set.

\section{RESULTS AND DISCUSSION}

The Performance the proposed system is used by principal component analysis. Different techniques of preprocessing steps are applied. Character acknowledgment is a strategy to find and perceive content put away in a picture, for example, a jpeg or a bmp picture, and convert the content into a PC perceived structure, for example, ASCII or opcode. Each character on the input image will be recognized by comparing with the templates prepared beforehand corresponding to every character.

1. Estimating the position of each character and extracting.

2. Normalizing the size and intensity of each character.

3. Calculating the feature values of each character.

4. Calculating the similarity by comparing the feature values between the extracted character and prepared templates.

5. Choosing a character that the similarity is highest recognition result.

The framework proposed to perceive the Numbers and English letters in order characters .The English language comprises of 26 characters of which 5 are vowels and 21 are consonant Though English letters can be of 2 cases viz. Capitalized and Lowercase, here we consider message just in capitalized in the image of Times new roman, Arial, Arial Block of the span of 72 and 48.There are numerous application for this acknowledgment.

1. Identification of stole Vehicles.

2. Automated parking attendant.

3. Red light camera.

4. Speed Enforcement.

5. Security

6. Customer Identification enabling personalized service.

7. Semiconductor device identification.

8. Item Identification.

Foremost part examination is a factual component extraction system which has been connected effectively. For format coordinating resize the picture into $74 * 50$.Most of them, utilize the dark scale picture [or] paired picture for highlight extraction .Here the yield of the preprocessing is fill picture. Before the fill commotion decrease are happen by utilizing Dilation. Fill picture separate the character and perceive the character by utilizing Euclidean separation .Identify the character dependent on the Euclidean separation between the character and of the character models.

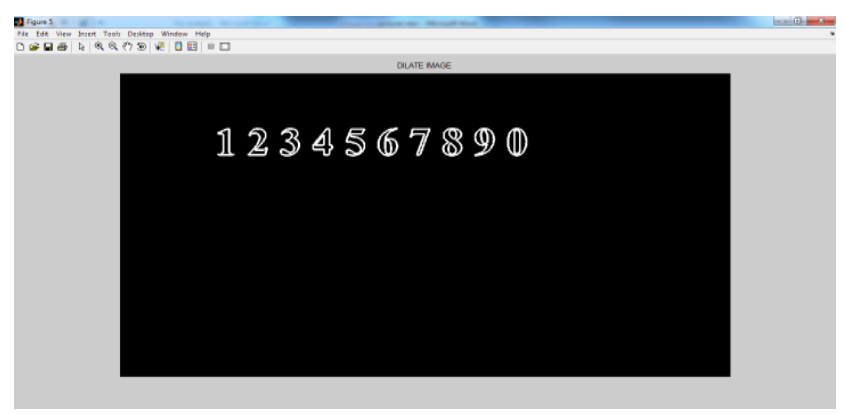

Fig 4: Conversion of Edge to Dilate Image

\section{CONCLUSION}

By and large, character acknowledgment incorporates content data gathering, data investigation and handling, data characterization and segregation, etc. Data gathering implies that dark of characters will be changed over into electrical sign, which can be contribution to pcs. Data gathering depends on paper nourishing instruments and photoelectric change gadgets in character acknowledgment peruser, flying-spots scanners, camcorder, photosensitive parts, laser scanners, and other photoelectric transformation gadgets. Data examination and handling kill the clamors and unsettling influence brought about by printing quality, paper quality, composing instruments and different variables. It can standardize size, deflexion, shade and thickness. Data arrangement and segregation can expel the clamors, standardize the character data, characterize the character data and yield the acknowledgment results

\section{0}

\section{REFERENCES}

1. Kumaravel A., Meetei O.N.,An application of non-uniform cellular automata for efficient cryptography,2013 IEEE Conference on Information and Communication Technologies, ICT 2013,V-,I-,PP-1200-1205,Y-2013

2. Kumarave A., Rangarajan K.,Routing alogrithm over semi-regular tessellations,2013 IEEE Conference on Information and Communication Technologies, ICT 2013,V-,I-,PP-1180-1184,Y-2013

3. Dutta P., Kumaravel A.,A novel approach to trust based identification of leaders in social networks, Indian Journal of Science and Technology,V-9,I-10,PP--,Y-2016

4. Kumaravel A., Dutta P.,Application of Pca for context selection for collaborative filtering,Middle - East Journal of Scientific Research,V-20,I-1,PP-88-93,Y-2014

5. Kumaravel A., Rangarajan K.,Constructing an automaton for exploring dynamic labyrinths,2012 International Conference on Radar, Communication and Computing, ICRCC 2012,V-,I-,PP-161-165,Y-2012 
of two multi-classification approaches for detecting network attacks,World Applied $\quad$ Sciences Journal,V-27,I-11,PP-1461-1465,Y-2013

7. Tariq J., Kumaravel A.,Construction of cellular automata over hexagonal and triangular tessellations for path planning of multi-robots,2016 IEEE International Conference on Computational Intelligence and Computing Research, ICCIC 2016,V-,I-,PP--,Y-2017

8. Sudha M., Kumaravel A.,Analysis and measurement of wave guides using poisson method,Indonesian Journal of Electrical Engineering and Computer Science,V-8,I-2,PP-546-548,Y-2017

9. Ayyappan G., Nalini C., Kumaravel A.,Various approaches of knowledge transfer in academic social network,International Journal of Engineering and Technology,V-,I-,PP-2791-2794,Y-2017

10. Kaliyamurthie, K.P., Sivaraman, K., Ramesh, S. Imposing patient data privacy in wireless medical sensor networks through homomorphic cryptosystems 2016, Journal of Chemical and Pharmaceutical Sciences .

11. Kaliyamurthie, K.P., Balasubramanian, P.C.An approach to multi secure to historical malformed documents using integer ripple transfiguration 2016 Journal of Chemical and Pharmaceutical Sciences 9

12. A.Sangeetha,C.Nalini,"Semantic Ranking based on keywords extractions in the web", International Journal of Engineering \& Technology, 7 (2.6) (2018) 290-292

13. S.V.GayathiriDevi,C.Nalini,N.Kumar,"An efficient software verification using multi-layered software verification tool "International Journal of Engineering \& Technology, 7(2.21)2018 454-457

14. C.Nalini,ShwtambariKharabe,"A Comparative Study On Different Techniques Used For Finger - Vein Authentication", International Journal Of Pure And Applied Mathematics, Volume 116 No. 8 2017, 327-333, Issn: 1314-3395

15. M.S. Vivekanandan and Dr. C. Rajabhushanam, "Enabling Privacy Protection and Content Assurance in Geo-Social Networks", International Journal of Innovative Research in Management, Engineering and Technology, Vol 3, Issue 4, pp. 49-55, April 2018.

16. Dr. C. Rajabhushanam, V. Karthik, and G. Vivek, "Elasticity in Cloud Computing", International Journal of Innovative Research in Management, Engineering and Technology, Vol 3, Issue 4, pp. 104-111, April 2018

17. K. Rangaswamy and Dr. C. Rajabhushanamc, "CCN-Based Congestion Control Mechanism In Dynamic Networks", International Journal of Innovative Research in Management, Engineering and Technology, Vol 3, Issue 4, pp. 117-119, April 2018.

18. Kavitha, R., Nedunchelian, R., "Domain-specific Search engine optimization using healthcare ontology and a neural network backpropagation approach”, 2017, Research Journal of Biotechnology, Special Issue 2:157-166

19. Kavitha, G., Kavitha, R., "An analysis to improve throughput of high-power hubs in mobile ad hoc network" , 2016, Journal of Chemical and Pharmaceutical Sciences, Vol-9, Issue-2: 361-363

20. Kavitha, G., Kavitha, R., "Dipping interference to supplement throughput in MANET" , 2016, Journal of Chemical and Pharmaceutical Sciences, Vol-9, Issue-2: 357-360

21. Michael, G., Chandrasekar, A.,'Leader election based malicious detection and response system in MANET using mechanism design approach", Journal of Chemical and Pharmaceutical Sciences(JCPS) Volume 9 Issue 2, April - June 2016

22. Michael, G., Chandrasekar, A.,"Modeling of detection of camouflaging worm using epidemic dynamic model and power spectral density", Journal of Chemical and Pharmaceutical Sciences(JCPS) Volume 9 Issue 2, April - June 2016.

23. Pothumani, S., Sriram, M., Sridhar, J., Arul Selvan, G., Secure mobile agents communication on intranet,Journal of Chemical and Pharmaceutical Sciences, volume 9, Issue 3, Pg No S32-S35, 2016

24. Pothumani, S., Sriram, M., Sridhar, Various schemes for database encryption-a survey, Journal of Chemical and Pharmaceutical Sciences, volume 9, Issue 3, Pg NoS103-S106, 2016

25. Pothumani, S., Sriram, M., Sridhar, A novel economic framework for cloud and grid computing, Journal of Chemical and Pharmaceutical Sciences, volume 9, Issue 3, Pg No S29-S31, 2016

26. Priya, N., Sridhar, J., Sriram, M. "Ecommerce Transaction Security Challenges and Prevention Methods- New Approach" 2016 ,Journal of Chemical and Pharmaceutical Sciences, JCPS Volume 9 Issue 3.page
no:S66-S68

27. Priya, N.,Sridhar,J.,Sriram, M.“Vehicular cloud computing security issues and solutions" Journal of Chemical and Pharmaceutical Sciences(JCPS) Volume 9 Issue 2, April - June 2016

28. Priya, N., Sridhar, J., Sriram, M. "Mobile large data storage security in cloud computing environment-a new approach" JCPS Volume 9 Issue 2. April - June 2016

29. Anuradha.C, Khanna.V, "Improving network performance and security in WSN using decentralized hypothesis testing "Journal of Chemical and Pharmaceutical Sciences(JCPS) Volume 9 Issue 2, April - June 2016

\section{AUTHORS PROFILE}

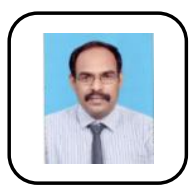

G.Michael Associate Professor, Department of Computer Science \& Engineering, Bharath Institute of Higher Education and Research, Chennai, India

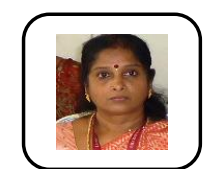

C. Nalini Associate Professor, Department of Computer Science \& Engineering, Bharath Institute of Higher Education and Research, Chennai, India

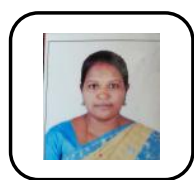

C. Geetha Assistant Professor, Department of Computer Science \& Engineering, Bharath Institute of Higher Education and Research, Chennai, India 